\title{
Research on Distance Education Media Based on Movie and Television Courseware
}

\author{
Wang Zhenghong ${ }^{1, a}$, Li Xiaoping ${ }^{2, b}$ \\ ${ }^{1}$ Beijing Institute of Technology Continuing Education and Modern Distance Education College , \\ Beijing 100081 \\ ${ }^{2}$ Beijing Institute of Technology Adult Education College , Beijing 100081 \\ a'wzhwzh@bit.edu.cn, ${ }^{\mathrm{b}}$ Ixpmx@x263.net
}

Keywords: Art of movie and television; Movie and Television Courseware; Educational Technology

\begin{abstract}
Through combining the advantages of art of movie and television, movie and television art education and educational technology, movie and television courseware has boarded the educational arena with overwhelming superiority. Thanks to its audio-visual integrated , comprehensive space-time and the combination of art and technology, the movie and television courseware has become the most promising distance education media.
\end{abstract}

\section{Development of Art of movie and television in Education}

By integrating literature, theater, painting, music, dance, sculpture, photography and other artistic essence in one, the movie and television courseware has a strong comprehensiveness. " $\mathrm{A}$ famous American scholar Daniel Bell thinks ' Contemporary culture is becoming a kind of visual culture instead of print culture.' Art of movie and television is transmitted through the audio-visual form, regardless of educational level anyone can contact with culture by cinematic transmission." Since the birth of human culture, humanity's thought intermediary system has changed from behavioral thinking to language symbolic thinking, and then went to digital thinking. Human is in the linear logic thinking when he understands the text along the semantic logic. But the art of movie and television puts human in the state of nonlinear thinking by creating an audio-visual language system with sound, shape, time and space.

1.1 As an industry, art of movie and television has a long history with more than a century and its theoretical researches can be summarized as four fields.

Art of Movie and Television: From the perspective of film art creation, we study how to create the film art works (including writing a play, shooting, post production, evaluation, etc.).

Social Study: Treat the art of movie and television as a cultural phenomenon and focus on the discussion of its historical value.

Psychology Study: Treat the psychological changes brought by art of movie and television as the research objects.

Education Study: Treat the art of movie and television as a mean of education or description.

The research results of the four fields have the relationship of cross and influence each other. Our study belongs to the fourth field and by fully drawing lessons from other fields' theoretical achievements, the art of movie and television formed the new concepts of movie and television courseware during the research in education.

1.2 Some traditional theories of education provide the theory support and guidance for art of movie and television providing auxiliary teaching.

Scaffolding Theory: Scaffolding theory refers to promote " A child or a novice can solve a problem, complete a task, or reach a goal” by providing temporary help.

Case-based Reasoning Theory: Learning based on case-based reasoning theory makes a new hypothesis for learners, gives a new definition to cognitive process, and puts forward some suggestions to improve learning, which can be realized by designing learning.

Cognitive Measure Theory: In a very indirect way, namely, by the methods of storytelling to subjects, we can design different types of behavior which is called "indirect story". In fact, this method has applied cognitive measures. 
Flow Theory: This theory is closely related to personal motivation, which emphatically describes individual control desire, deep feeling and pleasure under the condition of optimum experience. Studies show that intrinsic motivation and happiness experience can promote the learning.

\section{Foundation of Movie and television courseware Production}

Film and TV art education becomes an important branch of film and television art, and by introducing the ideas and methods of it, the movie and television courseware has become into a new medium for distance education.

2.1 Movie and television courseware is a new kind of remote education medium, which develops on the base of film and television art and film and TV art education.

“The 'film and television' here also includes the content about computer and network from the broad sense. In fact, movie education involving television and multimedia education has become a very normal phenomenon.” During the implementation of film and television, we can help students appreciate art of movie and television works and promote their comprehensive artistic accomplishment by the means of educational technology.

Movie and television courseware inherits the essence of art of movie and television and absorbs the teching experience and methods from film and television art education, which presents the educational forms of intuitive visual modeling, rich sound painting language and vivid content performance. By promoting the performance form of art of movie and television to different areas, movie and television courseware gives new vitality to film and television art.

2.2 As science and technology is the necessary condition for the birth of art of movie and television, the development of educational technology laies the foundation for movie and television courseware.

Film and television art and educational technology are important components of movie and television courseware, and the former is expressive force and the latter is means and carrier. In fact, it is an inevitable trend to integrate them for education, because they are indispensable. The application of modern educational technology in art of movie and television will realize new changes from means to content with the development of high-tech and the updating of concept of film and television art.

Interdisciplinary cross and professional penetration contribute to the generation of movie and television courseware in some extent. With the development of science and technology, interdisciplinary cross and professional penetration are more extensive in various disciplines. Movie and television courseware has the features of delivery and bridging, which makes it look independent, but in fact, it is actually associated. The application of art of movie and television in education has a new concept on today. It has a far-reaching significance to promote the concept of film and television art to various categories of different professions, which is regarded as a new distance education media.

\section{Creation Skills for Movie and television courseware}

Movie and television courseware fully uses the art's performance, by utilizing sound, images, montages and visual modeling, to act on human senses directly, so it has strong visual and verisimilitude. Such performance has charming for students, which can enable them to accept knowledge in a pleasant situation. Mr. Luxun once said, "It is better to chose the active movies instead of teachers to teach students and I'm afraid it will come true in future."

Movie and television courseware is not a mechanical and photographic reflect for academic content, in fact, it is a process which can make the esoteric knowledge into simplification by using art of movie and television language and many staff's careful design.

\subsection{Design idea of the script in movie and television courseware}

Early creation of movie and television courseware requires planning script which is divided into a script of course content and a shooting script. Before creation, the course script is written by 
teachers, while the shooting script is designed by designer staff during preparatory stage in the production process. The script of course content is the foundation of shooting, that is "the base of a drama" whose quality plays a decisive role on the courses' success. Movie and television courseware script should have a clear theme, concise content, strict structure, rich expression, clear reasoning and vivid word.

3.2 The creation of movie and television courseware teaching environmental design for learner-centered

The latest research trend of teaching technology is the learning environment which treats the students as the main body and treats the technology as the supporter. In this environment, the learner is committed to complete the goal-oriented tasks and create more powerful learning environment. Learning environment variables can affect the results of the study ,which include the timing, physical space, role plays and the combination of teaching methods and movie interactivity, etc. The research based on design emphasizes that through the cycle process of design, implementation, analysis, and redesign, we can create creative learning environment.

3.3 Movie and television courseware fully draws lessons from the creation skills of art of movie and television during its production.

Through using the expression of montage, long takes and so on, we can form the organic unity of dynamic and static, seeing and hearing, rationality and emotion. The cinematic art language of mobile, fixed, extreme close-ups,etc. used by camera can represent the curriculum knowledge incisively and vividly.

\section{The Advantages and Significance of The Application of Movie and television courseware in Teaching}

During movie and television courseware learning process, learning is a ring set of events that the students' learning is equivalent to a process of exploration, in which there are story line, dramatic conflict and students can solve various difficulties and problems by playing roles. Behavioral psychology acknowledges that "learners continually solve problems, and the correct answer feedback can call for students' continuing conditioned reflex of their behavior, which will enhance the learners understanding of knowledge."

\subsection{Diversity and cross-cutting in favor of expanding the content of different teaching}

The movie and television courseware integrates the digitalize audio, video and other information to remove the boundaries existing in a variety of disciplines, and make the teaching process become fun and dramatize, especially the course content will be materialized by using dynamic images. In practice, the creation of movie and television courseware is ever-changing with the areas of knowledge changing. By using new media, new space concepts and new ways of thinking, the movie and television courseware will help students enhance their abilities of cognition, adaptability and creativity for knowing the subject and object of curriculum.

4.2 Create a lively and interesting teaching situation, and intuitive interpretation for enhancing interest in learning

Dynamic characteristics itself is the basic characteristics of art of movie and television. Dynamic things are better than static things in attracting attentions. By making the static to dynamic and making the silence to sound, we can make the boring curriculum become deductive impressive. Vivid pictures, standard and realistic readings, pleasant background musices and interesting wit games can take students into a loose and happy learning environment.

In movie and television courseware, the application of digital and special effects can make students more easily enjoy a pleasure from the frames and expression skills of movie and television works.

\subsection{Break the limit of time and space and extend and broaden teaching space}

Through using images, sounds, colors and animations to convey information, movie and television courseware solves the teaching difficulties caused by time and space constraints, to make course more easily understood and mastered, and train the ability of students getting, analyzing and 
dealing with information.

4.4 Propose branch teaching philosophy and design different learning paths according to different needs, which possesses self- enlightenment and gradualness

The movie and television courseware is the product of art and science with intuitive, vivid, credible and strong infection characteristics. Diverse information acts on the student's various senses to make the relatively abstract and boring material becomes vivid, and to make teaching space to expand and teaching model updated. The complementary and extension of different courses make the course content achieve the best combination. "The success of art education often does not depend on rational preaching, but depends on the media giving fair and reasonable accesses to be realized."

\section{References}

[1] Xu Jing: "film and TV education" in the eyes of mass culture, the "Journal of Anhui Agriculture University (SOCIAL SCIENCE EDITION), 2000 edition.

[2] Zhou Xing: "on film and TV art education" in twenty-first Century the art education pattern in higher normal education, carrying "research", Twelfth volumes sixth, 2000 edition.

[3] (United States) Arthur, Berger: "popular culture, media and daily life narrative", translated by Yao Yuan, Nanjing University press, 2000 edition.

[4] Li Nianlu: "Introduction" television technology, China Film Press, 1998 edition.

[5] Li Mang, Jin Lin: "Introduction to educational technology", Peking University Press, 2009 edition. 